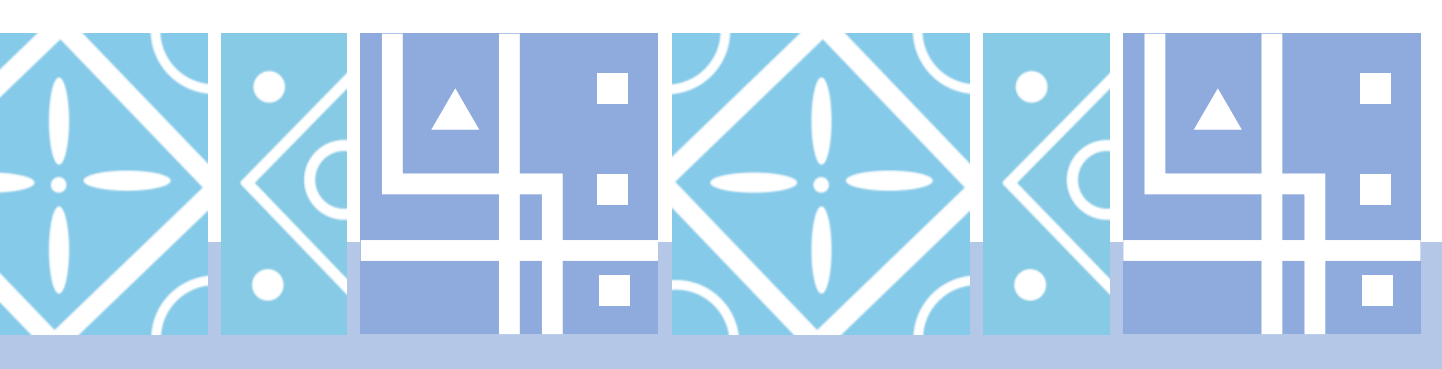

\title{
Orientações de Aprendizagem para o Ensino Remoto

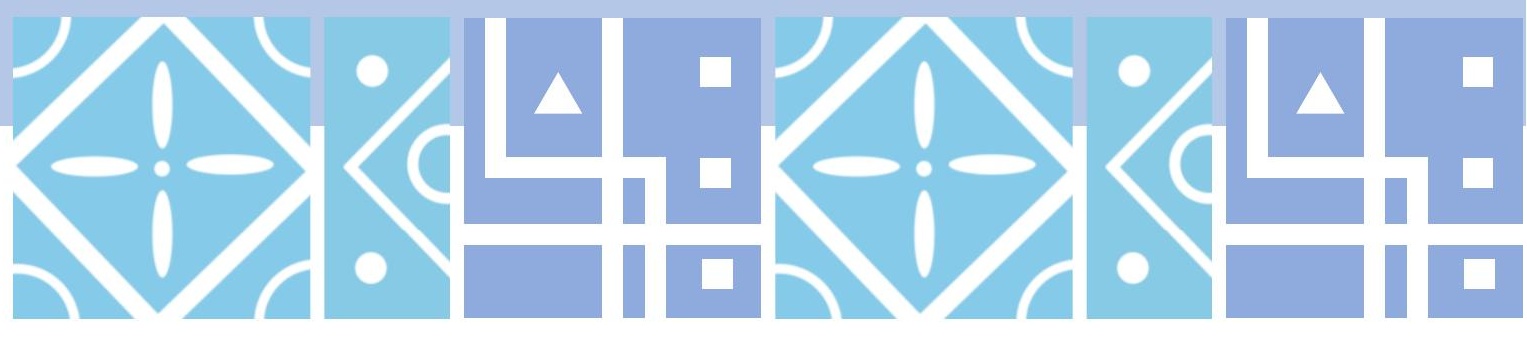

$1^{\circ}$ Ano dos Anos Iniciais - Ensino Fundamental

KELLY BIANCA CLIFFORD VALENÇA

CLÁUDIA SANTOS GONÇALVES BARRETO BEZERRA

FERNANDO MEDEIROS MENDONÇA

MARIANA DE CÁSSIA ASSUMPÇÃO

NEISI MARIA DA GUIA SILVA

Ftatuacaiúnas 


\section{Orientações de Aprendizagem para o Ensino Remoto}

\section{Autores}

Kelly Bianca Clifford Valença

Cláudia Santos Gonçalves Barreto Bezerra

Fernando Medeiros Mendonça

Mariana de Cássia Assumpção

Neisi Maria da Guia Silva

Projeto Gráfico, Capa, Revisão e Diagramação

Kelly Bianca Clifford Valença 


\author{
Corpo editorial \\ Bruno Nunes Batista \\ Instituto Federal Catarinense - IFC \\ Wildoberto Batista Gurgel \\ Universidade Federal Rural do Semi-Árido - UFERSA \\ André Luiz de Oliveira Brum \\ Universidade Federal do Rondônia - UNIR \\ Mário Silva Uacane \\ Universidade Licungo / Moçambique)
}

Editora-chefe

Viviane Corrêa Santos

Universidade do Estado do Pará - UEPA

Dados Internacionais de Catalogação na Publicação (CIP) de acor do com ISBD

\begin{tabular}{|l} 
V1520 \\
Orientações de Aprendizagem para o Ensino Remoto [recurso \\
eletrônico]: $1^{\circ}$ Ano dos Anos Iniciais - Ensino Fundamental / Kelly Bianca \\
Clifford Valença... [et al.]. - Ananindeua, PA : Itacaiúnas, 2020. \\
17 p. : il. ; PDF ; 3 MB. \\
Inclui bibliografia e índice. \\
ISBN 978-65-88347-11-9 \\
Doi 10.36599/itac-ed1.022 \\
1. Educação. 2. Aprendizagem. 3. Ensino remoto. I. Valença, Kelly \\
Bianca Clifford II. Bezerra, Cláudia Santos Gonçalves Barreto. III. \\
Mendonça, Fernando Medeiros. IV. Cássia, Mariana. V. Silva, Assumpção e \\
Neisi Maria da Guia. VI. Título. \\
10.36599/itac-ed1.022 \\
CDD 370 \\
CDU 37
\end{tabular}

Elaborado por Vagner Rodolfo da Silva - CRB-8/9410

Índice para catálogo sistemático:

1. Educação 370

2. Educação 37 


\section{Prefácio: Orientações gerais para a realização das atividades remotas}

O material aqui apresentado constitui parte do trabalho desenvolvido, durante o período de quarentena, pelo Departamento Multidisciplinar dos Anos Iniciais do Centro de Ensino e Pesquisa Aplicada à Educação (CEPAE) da Universidade Federal de Goiás (UFG). As propostas de atividades que compõem este exemplar são destinadas aos estudantes dos $1^{\text {os }}$ anos dos Anos Iniciais do Ensino Fundamental e devem ser realizadas com o acompanhamento de um responsável adulto.

Para dar seguimento ao processo de ensino-aprendizado já iniciado na modalidade presencial, o material em pauta integra orientações gerais envolvendo todas as áreas do conhecimento contempladas no $1^{\circ}$ ano.

É muito importante que as atividades propostas a esse período sejam realizadas com o auxílio e monitoração de um adulto disponível a incentivar a criança com carinho, primando pela compreensão, dedicação e superação dos seus limites.

Vivemos um momento diferenciado, que exige de nós uma atenção especial ao processo de estudo, capaz de motivar o estudante a realizar as atividades escolares em um ambiente físico que não é mais compartilhado com o colégio, mas, que se concentrou exclusivamente em seu lar. Por isto, defendemos o período do estudo como um momento agradável, de conexão entre família e criança, onde a prioridade deve ser promover uma atmosfera de tranquilidade e amor, sem cobranças excessivas ou punitivas, sempre reconhecendo o esforço e dedicação do estudante em cada etapa de trabalho. Para tanto, é fundamental ler histórias e criar uma rotina diária de estudo com a criança, primando pela qualidade da aprendizagem, em lugar da quantidade, e evitando, com isto, a realização das tarefas propostas ao período de trinta dias, de uma só vez. Nossa recomendação é que seja reservado o tempo de 1 h de estudo diário, de preferência no mesmo horário, onde a criança possa se concentrar e realizar de uma a duas tarefas por dia.

Ao final desta primeira etapa de trabalho remoto que estamos concebendo como introdutória, reavaliaremos os prazos estipulados bem 
como o volume de tarefas propostas. Buscaremos também ampliar as nossas ferramentas de trabalho, lançando mão de recursos tecnológicos contemporâneos, na medida em que consigamos garantir o acesso às tarefas, a todos os estudantes.

De antemão, orientamos as famílias que tentem manter uma rotina de estudos, mesmo que a criança conclua as atividades antes do prazo final estabelecido. Para ajudar nesta dinâmica, sugerimos a prática da leitura com a criança ou mesmo a interação com sites pedagógicos que selecionamos para esse público. Observem a nossa lista de material complementar ao final desta página. São sugestões que podem ampliar a experiência do estudo'.

Sabemos que o processo de trabalho não se dará da mesma maneira que ocorre no ensino presencial, mas, diante das circunstâncias atuais, faremos o nosso melhor possível para darmos continuidade à formação escolar dos nossos estudantes. A sistematização do nosso trabalho neste livro de orientações é um exemplo desta preocupação, pois reafirma o compromisso que temos com a especificidade dessa faixa etária, tão importante para nós, professores dos $1^{\text {os }}$ anos.

Ainda que a distância, desejamos um ótimo retorno aos alunos e seus familiares, com a certeza de que logo, logo poderemos compartilhar, também presencialmente, muitas experiências inesquecíveis.

Abraços carinhosos dos professores do $1^{\circ}$ ano,

Bianca, Cláudia, Fernando, Mariana e Neisi.

\footnotetext{
1 https://www.smartkids.com.br/, https://youtu.be/lohzWOaSh-E, http://projectoadamastor.org/audiolivros-para-criancas/, https://www.youtube.com/user/ticolicos, https://www.youtube.com/watch? $v=R N f X 3 m V A l m 4 \&$ feature=youtu.be, https://www.youtube.com/watch? $v=1 M 7 K i 0-M h 7 M \&$ feature=youtu.be, https://drive.google.com/drive/folders/IYEquiWILdTaZVzUwW3 J2gf9algFMWI? usp=sharing,
} 


\section{SUMÁRIO}

Apresentação da equipe de professores

Metodologia de trabalho

09

Objetivos gerais das diferentes áreas

Critérios de avaliação 13

Avaliação parcial das estratégias introdutórias do ensino remoto 14

Referências 16 


\section{Apresentação da equipe de professores}

O corpo docente do Centro de Ensino e Pesquisa Aplicada à Educação é composto por professores efetivos e substitutos da Universidade Federal de Goiás, Mestres e Doutores em sua maioria, especializados em suas respectivas áreas do conhecimento humano.

Destarte, contamos com uma equipe multidisciplinar, com ampla experiência no que tange à docência na Educação Básica, conferindo aos estudantes do $1^{\circ}$ ano dos Anos Iniciais uma oportunidade diferenciada de Educação Básica de qualidade.

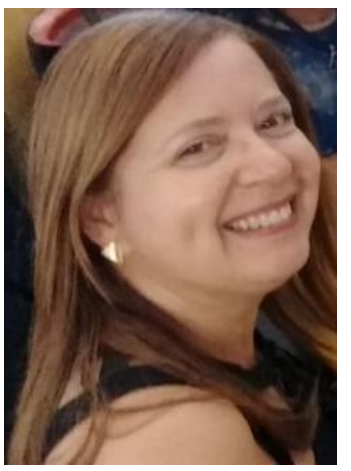

\section{Cláudia Santos Gonçalves Barreto Bezerra}

Professora Dra de Ciências Naturais, Geografia, História e Língua Portuguesa

Doutora em Ciências da Saúde pela Universidade Federal de Goiás (UFG), Mestre em Psicologia pela Pontifícia Universidade Católica de Goiás (PUC-GO), Especialista em Educação Infantil Montessoriana pela Deutsche Montessori Gesellschaft (DMG), Licenciada em Pedagogia pela Fundação Educacional Unificada Campo Grandense (FEUC).

Currículo Lattes: http://lattes.cnpq.br/8109756937099308

\section{Fernando Medeiros Mendonça}

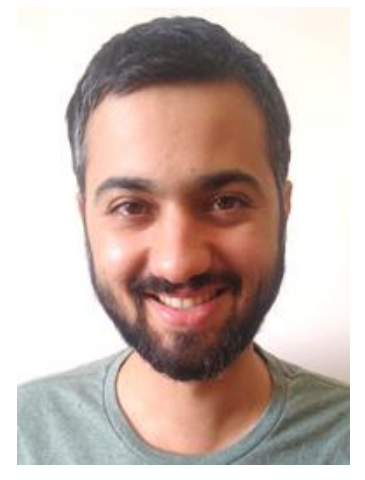

Professor Ms. de Educação Física

Mestre em Ensino na Educação Básica pela Universidade Federal de Goiás (UFG), Especialista em Docência do Ensino Superior pela Faculdade Brasileira de Educação e Cultura (FABEC), Licenciado em Educação Física pela UFG.

Currículo Lattes: http://lattes.cnpq.br/1432791208521528 


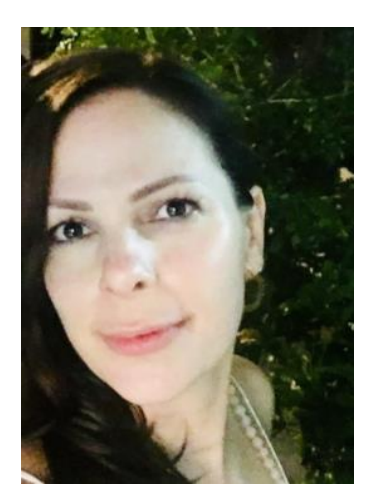

\section{Kelly Bianca Clifford Valença}

Professora Dr ${ }^{a}$ de Arte (Artes Visuais)

Doutora em Educação pela Universidade Federal de Goiás (UFG), Mestre em Arte e Cultura Visual pela UFG, Especialista em Arteterapia pela Faculdade Mauá de Brasília, Licenciada em Desenho e Plástica pela Universidade Federal de Pernambuco (UFPE).

Currículo Lattes: http://lattes.cnpq.br/6851081333978394

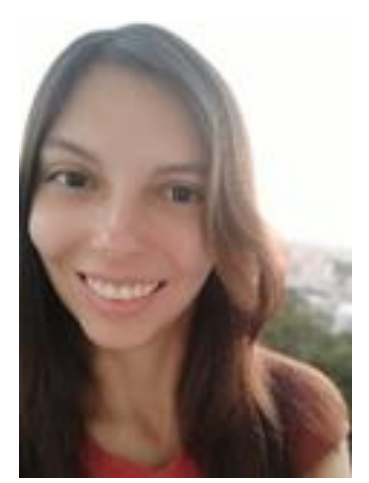

\section{Mariana de Cássia Assumpção}

Professora Dra de Ciências Naturais, Geografia, História e Língua Portuguesa

Doutora em Educação pela Universidade Estadual Paulista (UNESP), Mestre em Educação Escolar pela UNESP, Licenciada em Pedagogia pela UNESP.

Currículo Lattes: http://lattes.cnpq.br/5418513679571400

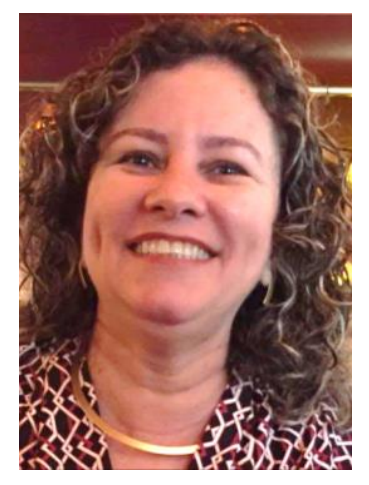

\section{Neisi Maria da Guia Silva}

Professora Dra de Matemática

Doutora em Educação pela Pontifícia Universidade Católica de Goiás (PUC-GO), Mestre em Educação pela Universidade Federal de Goiás (UFG), Especialista em Psicopedagogia pela UFG, Licenciada em Pedagogia pela UFG, Bacharel em Direito pela PUCGO.

Currículo Lattes: http://lattes.cnpq.br/9701252435619912 


\section{Metodologia de trabalho}

No processo de ensino-aprendizado desenvolvido com os $1^{\text {os }}$ anos dos Anos Iniciais do Ensino Fundamental do CEPAE, priorizamos a metodologia de trabalho com Projetos. Nesta perspectiva, a cada ano, uma unidade temática é adotada com o objetivo de promover um ponto de encontro comum entre as diferentes áreas do conhecimento exploradas no $1^{\circ}$ ano. A saber: Arte, Ciências Naturais, Educação Física, Geografia, História, Língua Portuguesa e Matemática. Assim, buscamos superar a perspectiva disciplinar de trabalho ao colocar os diferentes saberes em diálogo constante.

Nesta conjuntura multidisciplinar, a unidade temática adotada é $A$ construção do espaço no processo de aprendizagem. Outrossim, desmembramos esta unidade geral em eixos temáticos específicos, que serão contemplados no decorrer das escalas letivas 2 (tabela 1).

Tabela 1 - Detalhamento da Unidade Temática anual.

\begin{tabular}{|l|l|}
\hline \multicolumn{2}{|c|}{ A Construção do Espaço no Processo de Aprendizagem } \\
\hline I Escala Letiva & O Espaço Cotidiano \\
\hline II Escala Letiva & O Espaço do Corpo no Mundo \\
\hline III Escala Letiva & Crianças de Outros Tempos e Lugares \\
\hline IV Escala Letiva &
\end{tabular}

Esta organização estrutural do trabalho pedagógico que desenvolvemos no ensino presencial será adaptada ao trabalho remoto, a distância, visando minimizar prejuízos decorrentes do período pandêmico que nos encontramos.

2 Escala é a nomenclatura adotada pelo CEPAE para sinalizar o período de um ciclo de ensino-aprendizado. O ano escolar é composto por quatro escalas, sendo duas desenvolvidas no I semestre do ano letivo e duas no II semestre. Ao final de cada escala é realizada uma avaliação que compõe o histórico escolar do estudante. As escalas são previamente calendarizadas no início do ano letivo e se aplicam a toda a Educação Básica do colégio. 
Cabe mencionar que os conteúdos aqui elencados constituem apenas uma dimensão do trabalho desenvolvido, ao passo que buscamos articular propostas humanizadoras, capazes de contribuir com a vida do indivíduo para além dos muros institucionais, numa perspectiva de educação que também é sócio emocional e que, na nossa atual conjuntura, carrega em si a desafiadora tarefa de aproximar a criança da escola, ainda que a distância.

Com o intento de detalhar os conteúdos previstos para cada escala em questão, as figuras 1 a 3 ilustram a especificidade de cada área em diálogo com os eixos temáticos que serão explorados. Um maior detalhamento do plano de curso dessas áreas pode ser encontrado no Projeto Político de Curso (PPC), disponibilizado no site do Colégio (CEPAE, 2018). Vale mencionar que os conteúdos a seguir constituem uma previsão, passível de mudanças, conforme a necessidade de cada momento vivido no exercício de construção do conhecimento em regime remoto.

Figura 1 - Detalhamento dos conteúdos das diferentes áreas e eixo temático comum da l escala letiva.

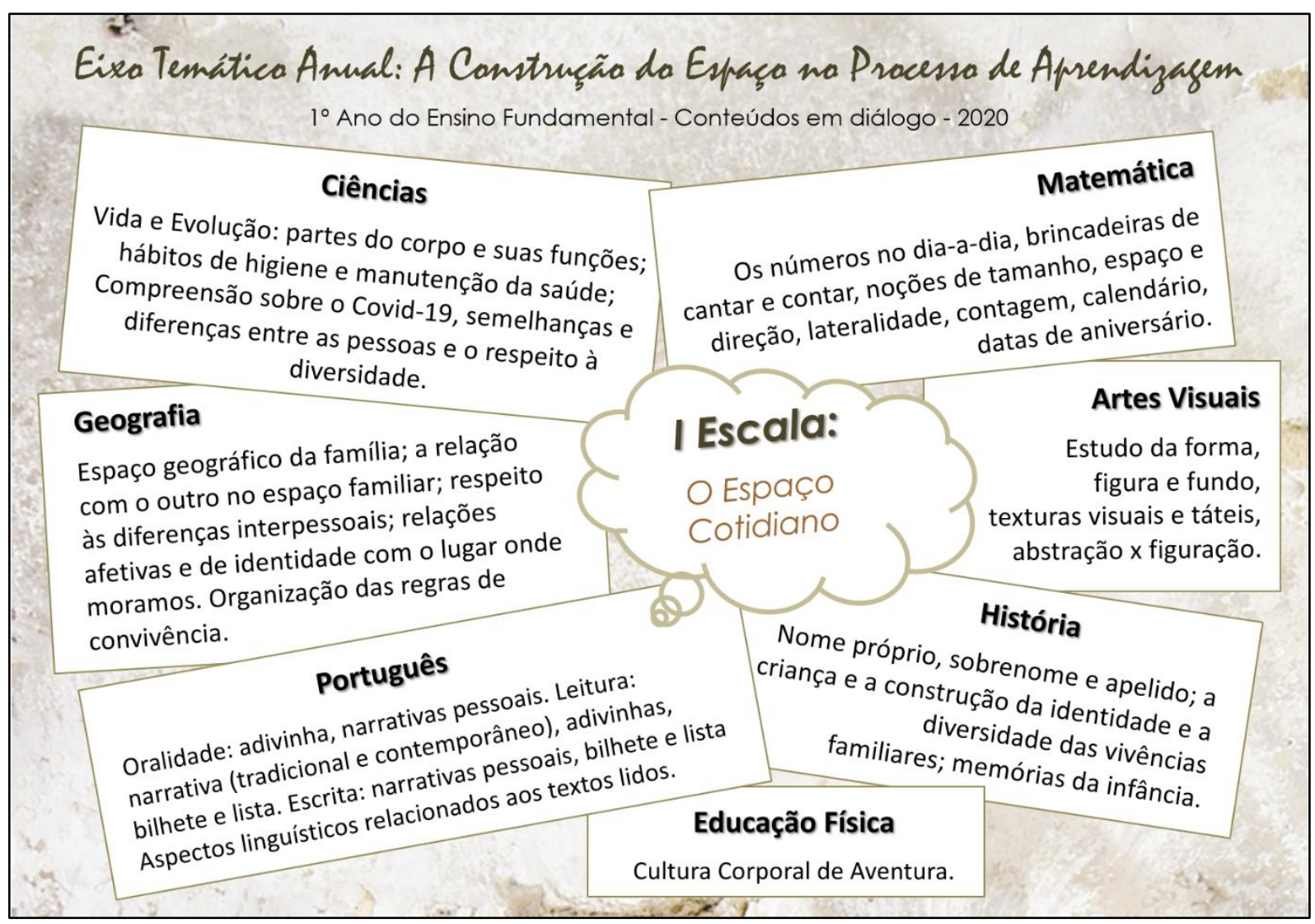


Figura 2 - Detalhamento dos conteúdos das diferentes áreas e eixo temático comum das II e III escalas letivas.

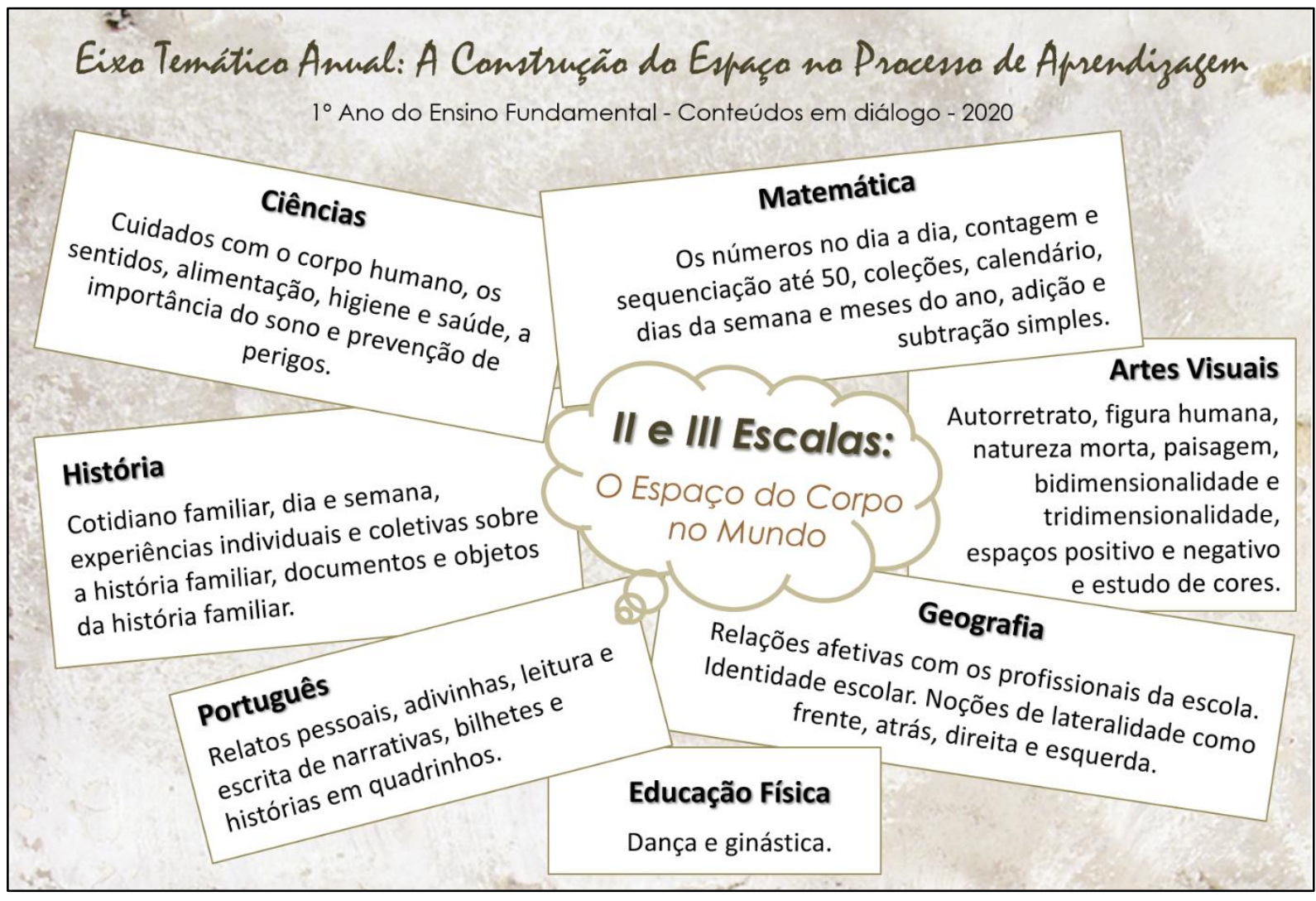

Figura 3 - Detalhamento dos conteúdos das diferentes áreas e eixo temático comum da IV escala letiva.

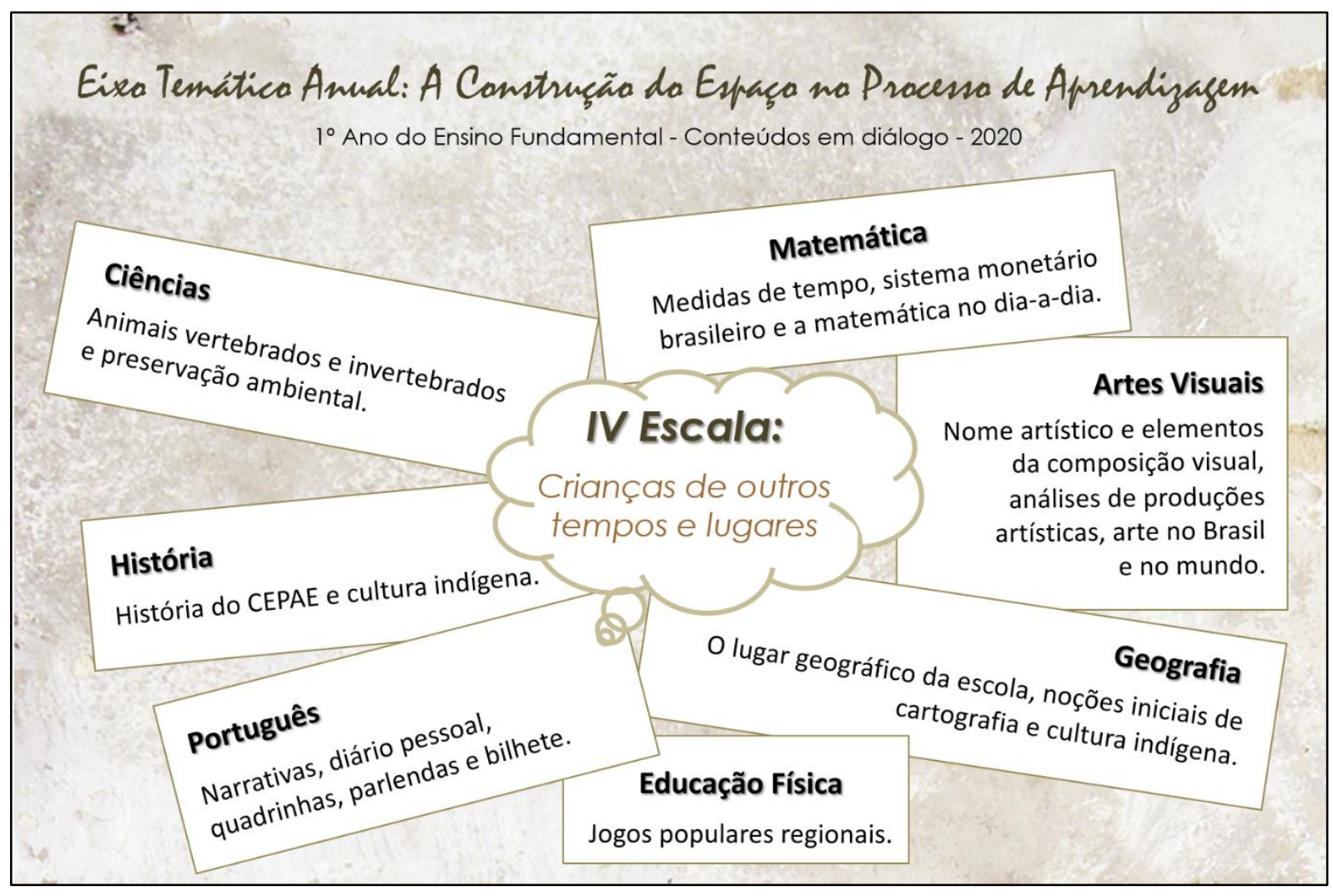




\section{Objetivos gerais das diferentes áreas}

Os objetivos gerais de cada área do conhecimento a seguir estão articulados ao que esperamos construir em termos de aprendizagem com os estudantes do $1^{\circ}$ ano dos Anos Iniciais do Ensino Fundamental.

Arte

(Artes Visuais)

Ciências

Naturais

Educação Física

Geografia

História

Matemática

Português
Explorar materiais e técnicas artísticas que auxiliem a construção do saber no que concerne a produtos, produtores, modalidades e estilos, concebendo a arte como expressão humana situada histórica e culturalmente.

Propiciar a construção dos conceitos científicos iniciais relacionados ao ambiente e ao corpo humano.

Explorar a cultura corporal como linguagem em diferentes manifestações, a exemplo de jogos, danças, lutas e ginásticas, de modo a valorizar a diversidade e a relação do homem com o seu semelhante e com a natureza.

Compreender como o espaço é apropriado pelas relações afetivas e de identidade na escola e no âmbito de convivência familiar.

Contribuir para que a criança perceba a disciplina como uma possibilidade de interpretação da sua história pessoal na família e na escola, valorizando e estabelecendo diferenças e semelhanças entre as suas experiências e as de seu grupo.

Desenvolver a capacidade do raciocínio lógico matemático, por meio de problemáticas cotidianas elaboradas pelo grupo ou encontradas em livros didáticos, envolvendo os seguintes eixos: Números e Álgebra, Geometria e Medidas e Análise de Dados.

Utilizar a língua portuguesa em diferentes situações enunciativas, seja na forma oral ou gráfica, visando a leitura e a escrita de textos diversos. 


\section{Critérios de avaliação}

Durante o período de ensino remoto, o processo de avaliação escolar dos estudantes não se dará da mesma maneira daquele praticado no ensino presencial. Os critérios adotados nesta fase de trabalho levarão em conta uma série de nuances necessárias às limitações que o contexto vivido acarreta. Por outro lado, este trabalho permanecerá se dando contínua e processualmente, de modo a colocar processos e produtos no mesmo patamar de importância e a considerar:

- A realização das tarefas propostas;

- A relação entre o enunciado das tarefas e os materiais apresentados pelos estudantes;

- A assiduidade nas devoluções, considerando os prazos préestabelecidos.

Cada etapa de atividades terá um prazo divulgado no enunciado do roteiro. É importante tentarmos respeitar esses períodos para que consigamos nos organizar melhor e manter o processo de avaliação em dia.

Devido à perspectiva de trabalho multidisciplinar em torno de eixos temáticos comuns aqui adotada, as atividades podem conter especificidades de uma única disciplina ou mais, variando de acordo com os planejamentos e objetivos de aprendizagem de cada etapa de estudo.

Por fim, mas não menos importante, a devolução das atividades pode se dar de diferentes maneiras e em diferentes suportes e formatos, a depender de cada tarefa. Neste contexto, é importante observar o quadro introdutório de cada atividade, onde constam todas as informações sobre os prazos e modos de entrega, recursos necessários, conteúdos trabalhados e objetivos de aprendizagem. 


\section{Avaliação parcial das estratégias introdutórias do ensino remoto}

Com o objetivo de avaliar o uso desta ferramenta introdutória de estudo e aprimorar a nossa metodologia de trabalho, solicitamos aos responsáveis pela criança que, após concluir todas as atividades do presente material, respondam as questões abaixo:

1. Preferência de letra para o material de estudo:

\begin{tabular}{|l|l|}
\hline & CURSIVA \\
\hline & FORMA \\
\hline & TANTO FAZ \\
\hline
\end{tabular}

2. $O$ que você achou do volume de tarefas para o período de 30 dias?

\begin{tabular}{|l|l|}
\hline & MUITA \\
\hline & POUCA \\
\hline & SUFICIENTE \\
\hline
\end{tabular}

3. Houve alguma(s) atividade(s) que a criança apresentou dificuldade para realizar? Caso sim, qual(is)? 
4. Qual(is) atividade(s) a criança apresentou mais facilidade para realizar?

5. O que você achou dessa experiência introdutória? 
Referência

CEPAE. Centro de Ensino e Pesquisa Aplicada à Educação. Projeto Pedagógico de Curso (PPC). Goiânia, 2018. 254 p. Disponível em:

<https://files.cercomp.ufg.br/weby/up/80/o/PPC_Versa\%CC\%83o_Final.pdf? 1 581521218>. Acesso em: 7 ago. 2020. 

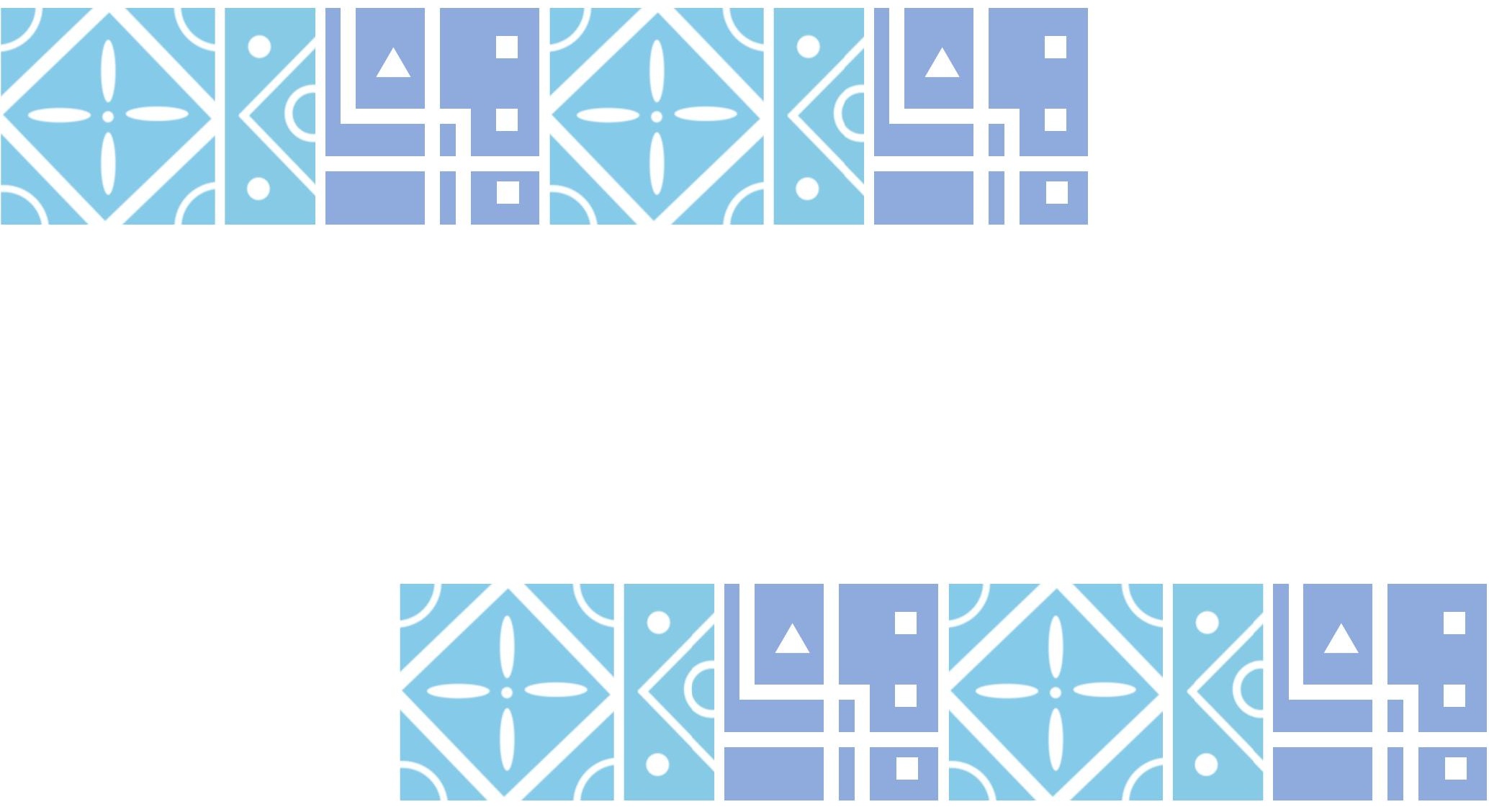